\title{
1. International migration and digital technology: an overview
}

\author{
Marie McAuliffe
}

\section{INTRODUCTION}

In an age of information overload and online connectivity, there is a strong sense that we are more closely linked transnationally than ever before in human history. Routine activities in day-to-day lives around the world speak volumes of the recent emergence of modern-day digital transformations. Sending e-mails, transferring money to family back home, searching online for information and advice, engaging in online shopping, posting comments on social media and listening to music are all fairly mundane and routine, so much so that such activities have become taken for granted in many societies around the world as access to digital technology has expanded at an unprecedented rate. Terms such as e-business, e-commerce, e-banking, e-trade, e-shopping, e-crime, e-book, e-reader, e-learning, e-form, e-dating, e-health, e-visa, e-passport and e-mail have become increasingly common in our lexicon. Over time, our social and economic interactions are increasingly mediated through digital systems and processes, placing much greater emphasis on digital technologies and reducing the need for personal interaction (Hirsh-Pasek et al., 2018).

The modern-day international migration narrative is deeply intertwined with the notion of betterment, whether that relates to individual attainment, household income or community resilience and coping strategies (Boyd, 1989; Castles, 2010; Massey, 1987; Stark and Bloom, 1985; Todaro, 1989). People migrate for better lives. This has long been the cornerstone of international migration research, analysis and policy (Massey et al., 1998, 2):

Like many birds, but unlike most other animals, humans are a migratory species. Indeed, migration is as old as humanity itself .... A careful examination of virtually any historical era reveals a consistent propensity towards geographic mobility among men and women, who are driven to wander by diverse motives, but nearly always with some idea of material improvement.

It can also be said that, in most recent and current discussions on migration, the starting point is usually numbers. Understanding changes in scale, emerging trends and shifting demographics related to global social and economic transformations, such as migration, helps us make sense of the changing world we live in and plan for the future. The current global estimate is that there were around 272 million international migrants in the world in 2019, which equates to 3.5 per cent of the global population. This is a very small minority of the world's population, meaning that staying within one's country of birth overwhelmingly remains the norm. The great majority of people do not migrate across borders, and it is thought that much larger numbers of people migrate within countries, although reliable statistics are not available on global estimates of internal migration.

The increase in international migrants has been evident over time - both numerically and proportionally - and at a slightly faster rate than previously anticipated, including because 


\section{Research handbook on international migration and digital technology}

of the prevailing forces of globalisation (Czaika and de Haas, 2015; IOM, 2019b; McAuliffe and Goossens, 2018; Triandafyllidou, 2018). Figure 1.1 shows the increase in international migrants over time since 1970 . While the number of international migrants has increased dramatically, in the context of the world's growing population, the proportional increases remain relatively modest.

This Research Handbook focuses on the dynamics that link international migration and digitalisation from economic, social, political and normative perspectives with reference to temporal and spatial dimensions. Temporality is particularly relevant in this domain as it is widely acknowledged that the pace of technological change through increasing digitalisation is intensifying at an unprecedented rate, creating uncertainty and disrupting societal norms (Muggah and Goldin, 2019; Skog et al., 2018). Long-held assumptions about societal values and their manifestations in economic, social and political systems and structures are being questioned, if not undermined, via recent technological advances in telecommunications technology, such as personal electronic devices and social media platforms, as the business sector scrambles to adapt to increasingly pervasive digitalisation (Skog et al., 2018). The digitalisation of communications that are reshaping the societies in which we live and the nature of our daily lives (and deaths) are causing us to re-think even the most fundamental concepts underpinning humanity, including its interaction with the natural world.

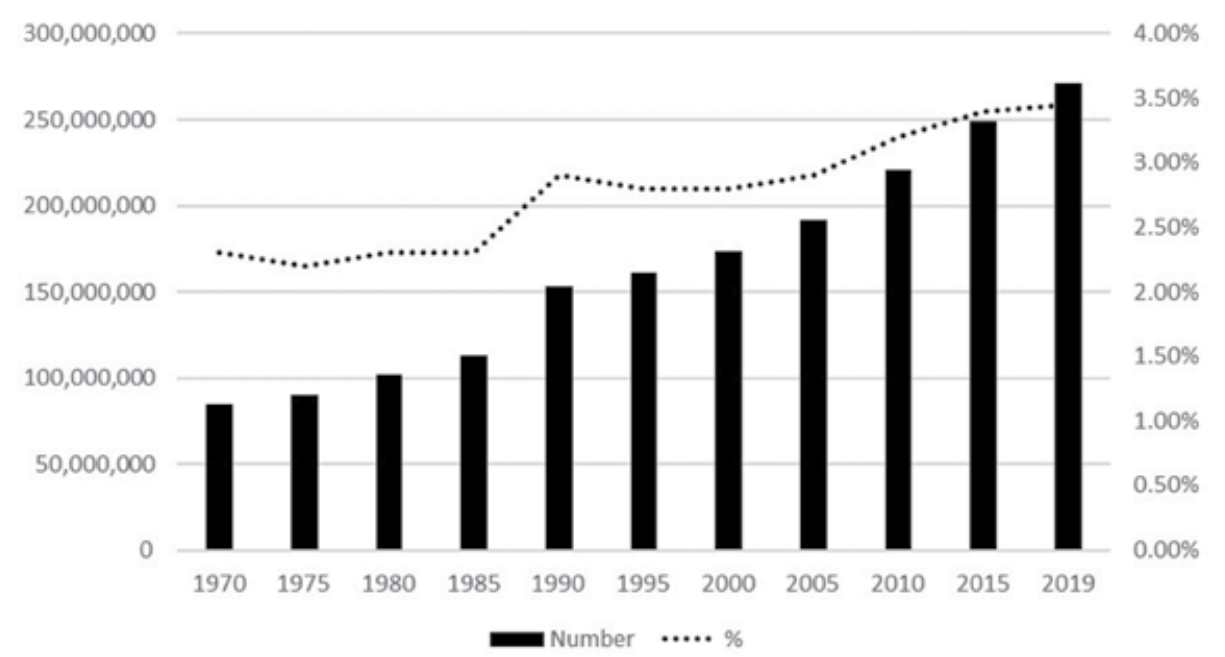

Source: UNDESA, 2019.

Figure 1.1 International migrants, 1970-2019

\section{AN AGE-OLD PHENOMENON IN A RAPIDLY EVOLVING DIGITAL LANDSCAPE}

The notion of migration is as old as humanity itself, and its complexities and multiple manifestations have been the subject of philosophical and scholarly enquiry, as well as law, for 
centuries. In the United Kingdom, for example, difficulties in determining parish responsibility as well as concerns over migration between parishes in search of more generous social support resulted in the Settlement Act of 1662, which sought to limit the ability of people to move between parishes (Bloy, 2002). More than a century later, and while the restrictions on internal migration were being softened, the first legislation to exclude foreign immigrants from entering the United Kingdom during peace time was enacted. The Aliens Act of 1793 allowed for the executive to exclude foreigners and was introduced in response to an increase in French nationals moving to Britain following the beginning of the French Revolution; the British government suspecting that some of the French immigrants would potentially bring 'anarchist' ideas with them (Aliverti, 2013). This was decades before the invention of the telegram and at a time during which news, information and ideas still had to be physically carried, rather than transmitted electronically. Even after the invention of the telegram in the mid-1800s, which greatly enabled international communications (although at great expense), news could be slow to travel as infrastructure was limited and, at times, diverted to national and international efforts. The experience of Paolina Roccanello, whose father had emigrated to Australia from Italy ahead of his family in order to set up the new home before his wife and children arrived - a common migration story - is briefly outlined in the text box below, highlighting just how much has changed in communications over the last 70 years.

\section{BOX 1.1 WAR-TIME SEPARATION: MIGRANTS' COMMUNICATIONS IN THE 1940s}

Eleven-year-old Paolina Roccanello arrived in Melbourne in April 1947 from Italy with her mother Elisabeta and younger brother Giuseppe on the SS Misr in the shadow of WWII (Huxley, 2007). The SS Misr carried over 600 passengers from 26 countries across Europe, the Middle East, East Africa and Southern Africa, including returning Australians, family migrants, displaced persons, Jewish refugees and South African footballers. The trip was long and arduous taking months and stopping in at many ports along the way (Boyatzis, 2010). Paolina was lucky to be reunited with her father who had emigrated to Australia eight years before, expecting his family to follow soon after. For all their war-time separation they received only one of his letters, which had taken five years to reach them (Huxley, 2007). Back then, there was no Internet, there were no mobiles or fax machines, and postal services were slow and often disrupted. Telegram and telephone communication was limited and costly, and had mostly been diverted by States to support fighting the war. After the war refugee movements beyond war-torn Europe were also heavily regulated by States (including under the United Nations). The UN coordinated repatriation, returns and resettlement of refugees to third countries. In today's terms, movements were extremely slow, highly regulated and very selective. Information on migration options for those who had been displaced was largely the monopoly of States, and opportunities for migrating to other regions were limited to formal channels (McAuliffe and Goossens, 2018).

\section{What is Digital Technology?}

The concept of digital technology has historically been closely related to computer technology, and in particular the significant advances in computerisation and increasing reliance on 


\section{Research handbook on international migration and digital technology}

computers in human and machine labour from the mid-twentieth century onwards (Rabinovitz and Geil, 2004). However, digital technology is broader, encompassing computer technology and non-computer technological innovations, such as those associated with smart phones and other devices (Ensmenger, 2012). And while many associate digital technologies with quantitative data, important nuances are central to understanding digital technology and its uptake (Ensmenger, 2012, 769):

It is important to note that this process of digitization is not the same as quantification .... The defining motivation of quantification is measurement; the principal goal of digitization, however, is manipulation .... Although the digital data in an MP3 file is numeric data, these numbers are not so much a measurement of sound as a model of sound. The value of that model is not so much that it is accurate as it is manipulable; MP3 data is valuable because it is easy to capture, store, communicate, analyze, and transform. It is only within a digital ecosystem of networks and devices that digital data becomes truly significant; but the rapidly increasing scale and scope of this ecosystem makes the imperative to digitize almost irresistible.

Digitalisation involves the creation of digital records or versions of all sorts of materials, such as paper/electronic documents and other information, photos, videos, music and other audio, biometric scans/imagery. Since 2005, we have witnessed an intensification of automatic digital capture throughout business and other sectors, resulting in massive increases in the number of digital interactions globally (Degryse, 2016). For example, it is estimated that in 2019 almost 300 billion emails were sent across the world, equivalent to around 805 million emails per day (Desjardins, 2019). The text box below places the recent estimates in a historical context that signposts major developments in the digitalisation of telecommunications over the last century.

\section{BOX 1.2 DIGITALISATION OF TELECOMMUNICATIONS OVER THE LAST CENTURY}

\begin{tabular}{ll}
\hline 1930 s - Invention of the modern computer. & In 2019 digitalisation was estimated to have resulted in: \\
1960s - E-mail entering use. & $\bullet 500$ million tweets \\
1980s - Cell phones introduced to the public. & $\bullet 294$ billion emails \\
1983 - GPS made available for public use. & $\bullet 4$ petabytes of data created on Facebook \\
1989 - Invention of the World Wide Web. & $\bullet 4$ terabytes of data created by connected cars \\
1993 - Internet is shared in the public domain. & $\bullet 65$ billion messages on WhatsApp \\
1994 - Start of blogs and social networks. & $\bullet 5$ billion searches made. \\
2001 - Start of 3G smart phones. & \\
2004 - Facebook is launched. & \\
2006 - Twitter is launched. & \\
2007 - Cloud computing; first iPhone launched. & \\
2009 - Start of 4G smart phones. \\
2010 - First iPad; rapid growth of tablet usage. \\
2018 - Start of 5G technology.
\end{tabular}

Sources: McAuliffe et al., 2017; Desjardins, 2019.

Key data on digital connectivity indicate that these rapid transformations are resulting in massive uptake globally, with 93 per cent of the world's population now having access to 
a mobile broadband network (ITU, 2020). In fact, as shown in Figure 1.2 there are now more mobile phone subscriptions globally than there are people.

Notwithstanding this massive growth, we are also witnessing the further entrenchment of a number of 'digital divides' along economic, geographic, demographic and gender lines. Digital technology usage is greater in developed than developing countries globally, while we also see higher uptake in urban settings over rural areas globally, by males compared to females and by youth over aged persons (ITU, 2020). Beyond telecommunications, the race for digitalisation is impacting industry (formal and informal) globally as well as the government sector as commercial and geopolitical competition intensifies (OECD, 2020; Skog et al., 2018; Wramsmyr, 2018).

\section{Migration and Digitalisation}

Alongside other key domains, international migration as a growing phenomenon in recent years and decades is increasingly affected by digitalisation processes and related technological advances. Migration scholarship has resulted in a rich body of knowledge on the impacts of technology through history, including during the industrial revolution, which spawned Ravenstein's 'laws of migration' in the late 19th century (Ravenstein, 1885, 1889). Much more recently a key focus of 'digitalisation' has been in the realm of information and communication, and how migrants, potential migrants, and their families and networks engage with migration through ICTs (Andersson, 2019; Metykova, 2010; Nedelcu, 2009). This was heightened further during the 2015-16 migration 'crisis' in Europe when the 'appification' of migration became highly visual and contested during public debates (McAuliffe, 2016; Sanchez, 2018; Zijlstra and van Liempt, 2017). Many of the chapters in this Research Handbook explore

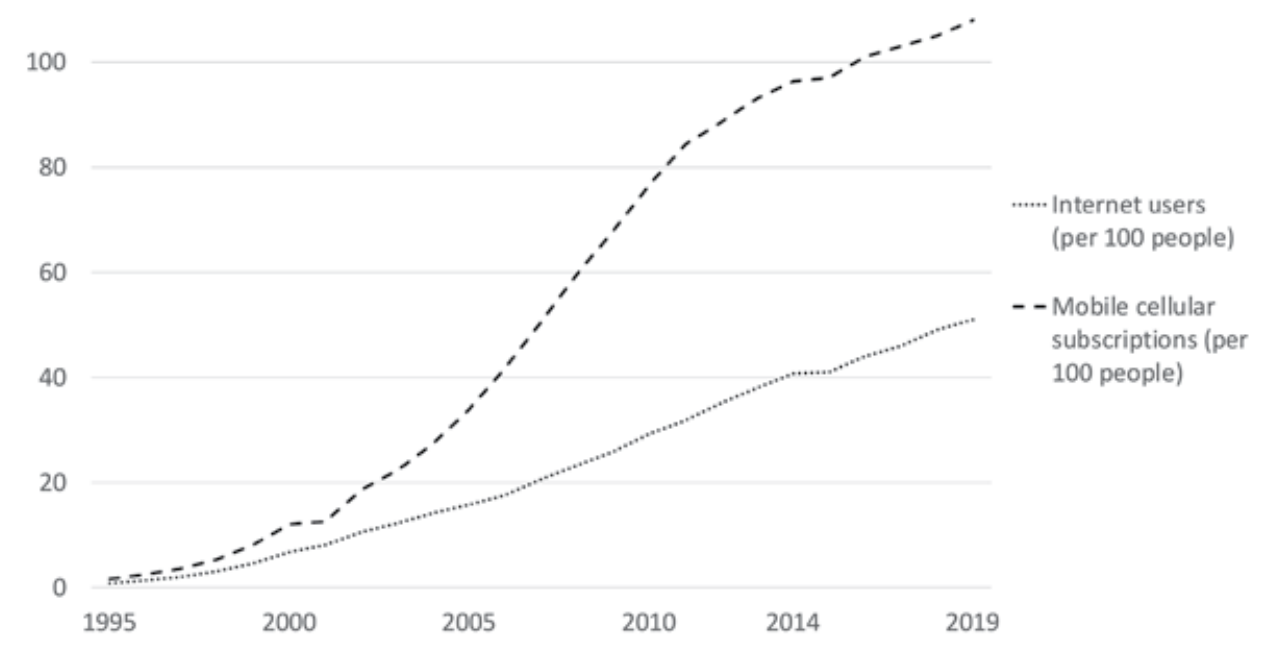

Source: ITU, 2020.

Figure 1.2 Global internet and mobile telephone access, 1995-2019 
the latest research findings on ICTs throughout the migration cycle, and for specific migrant groups (see discussion below).

In migration policy and practice, on the other hand, there has been significant investment by States in digitalisation and automation over recent years (and in some cases, decades), including so as to realise efficiencies and manage significant increases in volume. Australia, for example, embarked on its 'global working' program in the mid-1990s in order to move from a paper-based application processing system to a digital platform supported by service delivery partners in locations with limited/no online accessibility (Rizvi, 2004). One of the early online visa application systems resulted in between 15 and 20 basic application checks being automated, thereby significantly reducing processing time and staffing costs (ANAO, 2008; PwC, 2011). Initially, human visa officers were required to make final decisions on applications. However, the online platforms were further developed over time so that they provided automated decisions of low-risk applications, including through the use of profiling techniques, that did not require a human visa officer to be involved (Rizvi, 2004).

The consequences of rapid and ongoing digitalisation in the migration sphere can be profound, with significant impacts on people's lives, including as they relate to human rights. Digitalisation can result in privacy breaches of applicants, for example, such as has been experienced multiple times by immigration authorities in recent years on a mass scale (Farrell and Laughland, 2014; Karp, 2020). In addition to privacy and confidentiality issues, digitalisation can exacerbate existing inequalities of access to regular pathways by limiting visa/migration services to those who have online access and capabilities; the 'digital divide' occurs in many settings globally, including as it relates to migration (Cherewka, 2020; ITU, 2020). The gender dimensions are also highly relevant, with digital access being markedly different in gender terms in many locations around the world, most notably in more traditional cultures with patriarchal systems of power (Brinkerhoff, 2012; Said, this volume).

Further, digitilisation combined with machine learning automation can have extremely negative unintended consequences for officials and individuals alike. In 2016, for example, the United Kingdom revoked the visas of around 36,000 international students on the basis of a contracted language services company's AI human voice recognition analysis indicating that the students had used proxies in English language tests needed to secure visas. However, subsequent human analysis found that around 7,000 (or 20 per cent) of these students had been falsely accused of cheating, with the UK immigration appeals tribunal finding that the evidence used by the Home Office to deport the students had multiple frailties and shortcomings (Baynes, 2019).

\section{COVID-19 as the Digital 'turbo-charger'}

Technological advances since 2005 resulting in the so-called '4th industrial revolution' are profoundly changing how social, political and economic systems operate globally (Friedman, 2016; McKenzie, 2017; Schwab, 2016). We have been witnessing the rising power of 'big tech' (and the concomitant threat to State power structures), the increasing production capability for self-publishing of misinformation, the race by businesses to 'digitalise or perish', the massive increase in data being produced (mainly through user interactions) resulting in increasing 'datafication' of human interactions, and the rapid development and roll-out of AI capabilities within business and governments sectors (Beduschi and McAuliffe, 2021). Profound technological change was deepening before COVID-19, but has significantly inten- 
sified during the pandemic as States, industry and communities have quickly needed to adapt to physical isolation and immobility, which has presented challenges but also demonstrable opportunities and efficiencies. Deep digitalisation of an already digitalising world will most likely be one of the most significant long-term effects of COVID-19. What this will mean for migration and for migrants is of intense interest, and early reflections are offered in this volume (see McAuliffe and Blower), noting that the contents of this Research Handbook were compiled largely before or in the early stages of the pandemic.

\section{CONTENTS OF THIS HANDBOOK}

This Research Handbook is organised into six parts corresponding to the migration cycle (moving, borders, integration/reintegration, trends) as well as key domains of thematic examination and enquiry (research and analysis, public debates, migration futures). Central to the Handbook is recognition of the need to extend analysis beyond the more dominant realms in migration research, such as the heavy focus on (geo)political and related policy responses, while bringing together currently fragmented research and analysis covering perhaps the most significant technological change of the modern era, that of digital transformations.

The first part, entitled 'Understanding Migration Patterns and Processes: Digital Technology and Migration Research and Analysis', looks at the use of digital technology in migration research and analysis. This includes how digital technology and data-driven knowledge production may pose opportunities as well as risks for migrants and researchers, notwithstanding the increasing prevalence of digital technologies in the interdisciplinary research area of migration (Leurs and Witteborn in this volume). Two complementary chapters in this part also explore the significant challenges in quantifying migration patterns and processes through the analysis of migration data, which is moving from traditional sources into non-traditional digitally derived sources that increasingly encompass more diverse forms of mobility (Yildiz and Abel; McAuliffe and Sawyer). The application of network analysis, for example, to global migration patterns provides for new methods to understand macroscale patterning, however, it also presents challenges and limitations, including ethical ones, methodological ones, socio-technological ones and research reproducibility (Danchev and Porter). Likewise, the fast-moving and increasingly influential area of data visualisation is outlined in this part, with a particular focus on how migration data visualisations are connected to the long-standing 'politics of statistics' and their representations (Allen in this volume). As digitalisation deepens and sectors adapt, the production of data visualisation becomes increasingly important, most especially in the education sector as the next generations move away from static textbooks to interactive platforms able to present analytical representations of statistical and other forms of data in real time. Overall, the implications of digital technologies for fieldwork, analysis and related enquiry into migration all around the world are profound. The ongoing 'datafication' of policy, practice and research may risk moving even scholarly endeavours that draw upon rigorous methods into the realm of social disconnectedness and into a sphere dominated by 'data points'.

The second part of this Research Handbook, entitled 'Digital Technology and the Act of Moving: (Im)Mobility, Barriers and Borders', looks into the first stage of the migration cycle and how digital technologies are increasingly facilitating, but also disrupting and preventing, movements. The use of ICTs by migrants in navigating migration journeys in perilous 
circumstances is examined, with reference to the extent of social networking and reducing potential vulnerability through the migration process (Azhar, Vannini, Newell and Gomez). On the one hand ICTs enable pre-departure considerations of migration and the gathering of information and advice right the way through to navigating issues in destination countries. On the other hand, ICTs also have the potential to mask or obscure the very high risks and dangers involved in some migration journeys but considerably reducing social proximity and increasing the perception of feasibility - a serious double-edged sword for migrants, authorities and the civil society groups involved in supporting migrants' human rights. In exploring a subset of this broader topic, the role of ICTs in migrant smuggling processes is critically examined with reference to the latest research and analysis available (Papanicolaou, Diba and Antonopoulos). The 2015 and 2016 mass movements into and through Europe raised the issue of migrant smuggling to new heights in political, policy and operational spheres as hundreds of thousands of migrants (including refugees) made their way to specific destination countries in Europe from adjacent areas, principally Turkey. The research community was similarly affected and the long-standing scholarship on migrant smuggling dynamics saw heightened interest and output in the wake of Syrian refugees' (and others) use of smart phones during their journeys and to integrate into their new communities - the so-called 'appification' of migration (McAuliffe, 2016). The growing virtual mountain of user-generated data is being increasingly utilised to critically analyse migration and mobility patterns and processes in a range of geographies, including the movements of forced migrants (such as refugees). A key source is call data record analysis, which is explored in a case study chapter on how CDR has been utilised to support the Data for refugees Challenge in Turkey, including the data gaps, biases, ethical and privacy issues that need to be addressed when drawing upon such sensitive data (Salah, this volume).

Digital technologies are increasingly being deployed by migration authorities in a variety of settings, most notably at borders and prior to entry, through automated visa processing. However, while efficiencies can be realised and increases in volume better managed, the lack of transparency and oversight raises concerns about development and deployment in light of the profound human rights ramifications and real impacts on human lives (Molnar). These issues are also arising given the increasing use of drones in the management and control of land and sea borders, with drones being used not only by government authorities but also by criminal groups in their illicit operations. There has been a proliferation of drone technology as the costs have reduced dramatically, opening up opportunities for others to access and use the technology in migration settings, including greater numbers of non-state actors (Koslowski). This presents major political and ethical challenges, and with drone technology only becoming more sophisticated by the day, the implications for drone technology use in a wider variety of settings are profound.

Part III of this Research Handbook, entitled 'Integration, Reintegration and Migrants' (Digital) (Virtual) (Transnational) Identities', examines the impacts of digital technology during migrants' stay and integration in destination countries as well as after their return home to origin. The part explores how migrants themselves utilise digital technology as they adapt to new communities and seek to forge safe and meaningful lives in unfamiliar locations while remaining connected to home.

In most settings, digital technology has become the 'lifeline' for migrants, and in some cases can mean a matter of survival in highly dangerous settings - a matter of life or death (Gallagher and McAuliffe, 2016; Sanchez, 2018). For those wanting to settle into a new society 
and feel a sense of inclusion, ICTs can present a short-cut to belonging through facilitating migrants' agency during integration journeys. Digital tools and expanding uptake represent opportunities for inclusion in destination countries while also supporting connectedness and knowledge transfer to origin communities (Bauloz). The particularities of refugees' inclusion through the provision of virtual higher education extends this discussion to the examination of a particularly vulnerable and significant group (Reinhardt, Zlatkin-Troitschanskaia, Happ and Nell-Müller). On the other hand, ICTs and social media platforms can also be used by migrants to be 'here and not here', including in the context of religious transnationalism and the realisation of digitally based faith in migration settings (Nyamnjoh). While in other settings, such as those involving international students and parents in transnational households, connectivity can raise rather than reduce parental burdens in sociocultural contexts that have not yet fully adjusted to new familial roles and practices (Wang and Lim).

The role of digital technology is markedly under-researched in the study of return migration and reintegration dynamics, and yet return migration processes are increasingly reliant on digital technology to take effect (especially on the part of State actors). This under-explored area is examined in depth with reference to existing evidence on both the benefits and risks offered by ICTs in return and reintegration contexts, while also highlighting knowledge gaps and potential policy responses (Majidi, Kasavan and Harindranath).

The next part in the Research Handbook-Part IV on 'Connectivity and Migration: Trends and Impacts' - takes a big picture look at how digital technology is impacting particular migrant groups and migration corridors, including migrant workers, high-skilled tech professionals and also along gender lines. Digital technology holds the promise to support the engagement of migrant workers more rapidly, cheaply and at greater scale, however, despite being often seen as a panacea, digital solutions rarely improve migrant workers' precarity (Kintominas, Berg and Farbenblum). A key aspect of labour migration that has risen in prominence in recent years is the analysis of international remittances of migrant workers, and most notably the development impacts over the longer term. The growth in remittances has come about during an era of rapid digitalisation, and yet the economic and technological barriers that have resulted in uneven remittance flows and wide variance in transaction costs have been of modest interest in migration scholarship. The links between remittance flows and development can be traced to mobile money and financial-digital inclusion (including along gender lines), and there is much room for improvement before many communities globally, but most especially in sub-Saharan Africa, are able to realise the maximum benefits of international remittances from diaspora worldwide (Kitimbo). On the other hand, and in other geographic contexts, long-term policy planning by India has enabled and facilitated the emigration of Indian tech professionals on a major scale, requiring realignments and adjustments to education and skills development streams both inside and outside India over time (Khadria and Mishra).

The feminisation of migration has long featured in scholarship as well as more recently in policy and programmatic responses to aspects of international migration (IOM, 2019a; Piper, 2008). Less prominent are examinations of the intersections of digital technology and gender in the context of migration and displacement, however, with the increasing awareness of the centrality of gender in the development, production and deployment of tech globally, deeper examination of this topic in the field of migration studies is much needed (Saïd). Closely related, but conceptually distinct, the issue of digital technology and family life in migrant settings highlights the complex array of opportunities and threats to transnational families posed 
by connectivity and the regulation and implementation thereof. Adaptable and rights-based regulation and cooperation frameworks and regimes are central if countries and regions are to realise the full potential of technology to support the increasing number of transnational families globally (Bhabha, Bhatia and Peisch).

Increasingly important in all realms of modern societies, digital technology has come to dominate the means and manner of political, social and economic discourse, and increasingly the content of such discourses as unfiltered self-publishing of (ill-informed) opinion becomes the norm. With this in mind, the next part focuses on technology and public debates on migration. The exploitation of online platforms to spread disinformation challenges accurate and balanced public debates to manipulate segments of the public in order to further political ambitions of power, particularly those of the far-right (Culloty and Suiter). The logical extension of such tactics of political actors, combined with the organic engagement of 'networked' publics of all types and from all walks of life, is ultimately resulting in polarisation between anti-immigrant conservatives and pro-immigrant liberal publics that undermines democratic processes (Ojala). In contrast, platforms are also means of human rights advocacy by migrants themselves, including those caught up in highly (geo)politicised contexts such as Nauru and Papua New Guinea. Asylum seekers and refugees detained as part of Australia's offshore processing policy recount experiences using new media platforms to improve specific situations and encourage the formation of social movements to champion human rights in real time (Cannon and Kanapathi).

In the final part, entitled 'Digital Migration Futures', a range of strategic issues underpinning the digitalisation of migration and mobility are contemplated. With digital technology increasingly pervasive in nearly all public domains, migration cannot be immune from deeper transformations of societies currently underway. Technologies appear throughout migration processes, ultimately transforming the categories of place, time and action, and giving rise to a multiplicity of actors and institutions related to migration issues (Dijstelbloem). To better understand the impacts of the digital transformations of migration, forecasting methodologies are embracing technological innovation, especially in the information and communication domain, but also by providing new ways of measuring migration. Technical and conceptual limitations seek to combine traditional and new forms of migration data; however, forecasting remains indicative rather than quantitative in light of the inherent complexity and uncertainty of migration processes (Wiśniowski). Notwithstanding the limitations of forecasting migration flows and trends, the technological power of the State greatly outweighs the tech capacity of migrants (including refugees) through all aspects of the migration cycle. The recent experiences of migrants vis-à-vis large tech providers provide worrying signs of surveillance and control, rendering individuals and vulnerable groups open to exploitation and abuse during migration (Korkmaz). In the final chapter of the Research Handbook, an early glimpse of how digital technology during COVID-19 is reshaping migration governance and practice is outlined. Written in the midst of the pandemic, and while national and international dynamics were evolving rapidly, the early signs indicate that securitisation rhetoric was bolstered during the initial weeks and months, thereby enabling the uptake of digital technology for both pandemic and non-pandemic purposes, such as broader population surveillance. Technological innovations can undoubtedly help mitigate the impacts of COVID-19; however, considerable concerns are being raised by scholars and civil society actors on the privacy and human rights implications of data collection and usage. The full implications for migration and mobility, privacy and security are as yet unknown; that said, alarming developments regarding the 
extent to which human rights principles have been so rapidly set aside during the pandemic are cause for major concern (McAuliffe and Blower).

\section{ACKNOWLEDGEMENTS}

Thanks are due to Edward Elgar Publishing for its interest in this research topic and for commissioning the Research Handbook, and with special thanks to Daniel Mather for his advice and encouragement throughout the process. Thanks also to IOM leadership for its support of migration research in a wide variety of settings, including academic and applied settings globally, and for support to enable this volume in particular (especially to Jill Helke, Gervais Appave and Wen Li). Thanks also to colleagues at the School of Demography at the Australian National University (Edith Gray and James Raymer) and at the Graduate Institute in Geneva (Cecilia Cannon and Vincent Chetail). Enormous thanks to all contributing authors, who persevered with this volume to see it through to the end notwithstanding the pandemic disruptions and delays (which for some people included coronavirus illness), and to Jenna Blower for helping to get the final manuscript ready for submission.

\section{NOTE}

The opinions, comments and analyses expressed in this chapter are those of the author and do not necessarily represent the views of any of the organisations or institutions with which the editor/author is affiliated.

\section{REFERENCES}

Aliverti, A. (2013) Crimes of mobility: Criminal Law and the regulation of immigration. Hoboken, NJ: Taylor \& Francis.

Andersson, K. (2019) Digital diasporas: an overview of the research areas of migration and new media through a narrative literature review, Human Technology, 15(2): 142-180.

Australian National Audit Office (ANAO) (2008) DIAC's Management of the Introduction of Biometric Technologies. Department of Immigration and Citizenship, Australia.

Baynes, C. (2019) Government 'deported 7,000 foreign students after falsely accusing them of cheating in English language tests', The Independent, 14 June.

Beduschi, A. and M. McAuliffe (2021) AI, migration and mobility: implications for policy and practice, M. McAuliffe and A. Triandafyllidou (eds) World Migration Report 2022, IOM: Geneva. Forthcoming.

Bloy, M. (2002) The 1662 Settlement Act, The Victorian Web: Literature, history and culture in the age of Victoria, at http://www.victorianweb.org/history/poorlaw/settle.html (accessed on 20 December 2020).

Boyatzis, P. (2010) A new life, The Empire Patrol Disaster website, at http://www.empirepatrol.com/ index.htm (accessed on 20 December 2020).

Boyd, M. (1989) Family and personal networks in international migration: recent developments and new agendas, International Migration Review, 23(3): 638-670.

Brinkerhoff, J.M. (2012) Digital diasporas' challenge to traditional power: the case of TibetBoard, Review of International Studies, 38(1): 77-95.

Castles, S. (2010) Understanding global migration: a social transformation perspective, Journal of Ethnic and Migration Studies, 36(19): 1565-1586. 


\section{Research handbook on international migration and digital technology}

Cherewka, A. (2020) The Digital Divide Hits U.S. Immigrant Households Disproportionately during the COVID-19 Pandemic, Migration Policy Institute: Washington DC, at https://www.migrationpolicy .org/article/digital-divide-hits-us-immigrant-households-during-covid-19 (accessed on 20 December 2020).

Czaika, M. and H. de Haas (2015) The globalization of migration: has the world become more migratory?, International Migration Review 48(2): 283-323.

Degryse, C. (2016) Digitalisation of the Economy and its Impact on Labour Markets, ETUI Working Paper 2016.02, European Trade Union Institute, at https://www.etui.org/Publications2/Working -Papers/Digitalisation-of-the-economy-and-its-impact-on-labour-markets (accessed on 20 December 2020).

Desjardins, J. (2019) How Much Data is Generated Each Day? eNewsWithoutBorders, 23 April, at https://enewswithoutborders.com/2019/04/23/how-much-data-is-generated-each-day/ (accessed on 20 December 2020).

Ensmenger, N. (2012) The digital construction of technology: rethinking the history of computers in society, Technology and Culture 53(4): 753-776.

Farrell, P. and O. Laughland (2014) Review blames Immigration for data breach exposing 10,000 detainees, The Guardian, 12 June, at https://www.theguardian.com/world/2014/jun/12/review-blames -immigration-data-breach-detainees (accessed on 20 December 2020).

Friedman, T. (2016) Thank you for Being Late: an Optimist's Guide to Thriving in the Age of Accelerations. New York, NY: Farrar, Straus and Giroux.

Gallagher, A. and M. McAuliffe (2016) South-East Asia and Australia, in Migrant Smuggling Data and Research: A Global Review of the Emerging Evidence Base (eds M. McAuliffe and F. Laczko), IOM, Geneva, at https://publications.iom.int/system/files/smuggling_report.pdf (accessed on 20 December 2020).

Hirsh-Pasek, K.M. Schlesinger, R. Michnick Golinkoff and E. Care (2018) The New Humanism: Technology should enhance, not replace, human interactions, The Brookings Institution, 11 June, at https://www.brookings.edu/blog/education-plus-development/2018/06/11/the-new-humanism -technology-should-enhance-not-replace-human-interactions/ (accessed on 20 December 2020).

Huxley, J. (2007) When a Boat Came In: The First Wave: Beyond a White Australia, at www.smh.com .au/multimedia/misr/story.html (accessed on 20 December 2020).

International Organization for Migration (2019a) Supporting Brighter Futures: Young Women and Girls and Labour Migration in South-East Asia and the Pacific. IOM: Geneva.

International Organization for Migration (2019b) World Migration Report 2020. IOM: Geneva.

International Telecommunication Union (ITU) (2020) Measuring Digital Development: Facts and Figures 2020. Geneva: ITU.

Karp, P. (2020) Government investigates data breach revealing details of 774,000 migrants, The Guardian, 4 May, at https://www.theguardian.com/australia-news/2020/may/05/government-investigates-data -breach-revealing-details-of-774000-migrants (accessed on 20 December 2020).

Massey, D.S. (1987) Understanding Mexican migration to the United States, American Journal of Sociology, 92: 1372-1403.

Massey, D.S., J. Arango, G. Hugo, A. Kouaouci and A. Pellegrino (1998) Worlds in Motion: Understanding International Migration at the End of the Millennium. Oxford: Oxford University Press.

McAuliffe, M. (2018) The link between migration and technology is not what you think, Agenda, 14 December, World Economic Forum, Geneva, at www.weforum.org/agenda/2018/12/socialmedia-is -casting-a-dark-shadow-over-migration/ (accessed on 20 December 2020).

McAuliffe, M. (2016) The appification of migration. A million migrants? There are apps for that. APPS Policy Forum, Asia and the Pacific Policy Society, 20 January, at www.policyforum.net/the -appification-of-migration (accessed on 20 December 2020).

McAuliffe, M. and A.M. Goossens (2018) Regulating international migration in an era of increasing interconnectedness, in Handbook of Migration and Globalisation (ed. A. Triandafyllidou). Cheltenham, UK and Northampton, MA, USA: Edward Elgar Publishing, pp. 86-104.

McAuliffe, M., A.M. Goossens and A. Sengupta (2017) Mobility, migration and transnational connectivity, in World Migration Report 2018 (eds M. McAuliffe and M. Ruhs). Geneva: IOM, pp. 149-169, at www.iom.int/wmr/chapter-6 (accessed on 20 December 2020). 
McKenzie, F. (2017) The Fourth Industrial Revolution and International Migration, Sydney: Lowy Institute for International Policy.

Metykova, M. (2010) Only a mouse click away from home: transnational practices of Eastern European migrants in the United Kingdom, Journal for the Study of Race, Nation and Culture, 16(3): 325-338, at https://doi.org/10.1080/13504630.2010.482418

Muggah, R. and I. Goldin (2019) How to survive and thrive in our age of uncertainty, Agenda, World Economic Forum, Geneva, 7 January, at www.weforum.org/agenda/2019/01/how-to-survive-ourage -of-uncertainty-muggah-goldin/ (accessed on 20 December 2020).

Nedelcu, M. (2009) Migrants' new transnational habitus: rethinking migration through a cosmopolitan lens in the digital age, Journal of Ethnic and Migration Studies, 12(9): 1339-1356, at https://doi.org/ $10.1080 / 1369183$ X.2012.698203

OECD (2020) Digital Government Index (DGI): 2019, OECD, Paris, at http://www.oecd.org/gov/digital -government/oecd-digital-government-index-2019.htm (accessed on 20 December 2020).

Piper, N. (2008) Feminisation of migration and the social dimensions of development: the Asian case, Third World Quarterly, 29(7): 1287-1303.

Pricewaterhouse Coopers (PwC) (2011) Policy study on an EU Electronic System for travel Authorization (EU ESTA), PwC, Brussels, at https://ec.europa.eu/home-affairs/sites/homeaffairs/files/e-library/ docs/pdf/esta annexes en.pdf (accessed on 20 December 2020).

Rabinovitz, L. and A. Geil (2004) Memory bites: history, technology and digital culture. Durham, NC, and London: Duke University Press.

Ravenstein, E.G. (1885) The laws of migration, Journal of the Statistical Society of London, 48(2): 167-235.

Ravenstein, E. (1889) The laws of migration, Journal of the Royal Statistical Society, 52: 241-305.

Rizvi, A. (2004) Designing and delivering visas. People and Place, 12(2): 45-52.

Sanchez, G. (2018) Critical perspectives on clandestine migration facilitation: an overview of migrant smuggling research, Journal on Migration and Human Security, 5(1): 9-27.

Schwab, K. (2016) The Fourth Industrial Revolution: what it means, how to respond, Agenda, 14 January, World Economic Forum, Geneva.

Skog, D.A., H. Wimelius and J. Sandberg (2018) Digital Disruption, Business \& Information Systems Engineering, 60(5): 431-437, at https://doi.org/10.1007/s12599-018-0550-4.

Stark, O. and D. Bloom (1985) The new economics of labor migration, American Economic Review, 75: 173-178.

Todaro, M. (1989) Economic Development in the Third World. Fourth edition. New York, NY: Longman.

Triandafyllidou, A. (ed.) (2018) Handbook of Migration and Globalisation. Cheltenham, UK and Northampton, MA, USA: Edward Elgar Publishing.

United Nations Department of Economic and Social Affairs (UNDESA) (2019) International Migrant Stock 2019, at www.un.org/en/development/desa/population/migration/data/estimates2/estimates19 .asp (accessed on 20 December 2020).

Wramsmyr, A. (2018) Competition in the digitalization race, Adnavem, 13 March, at https://www .adnavem.com/blog/i-welcome-competition-in-the-digitalisation-race (accessed on 20 December 2020).

Zijlstra, J. and van Liempt, I. (2017) Smart(phone) travelling: understanding the use and impact of mobile technology on irregular migration journeys, International Journal for Migration and Border Studies, 3(2-3): 174-191. 